\title{
Status of Arbuscular mycorrhiza (AM) in nurseries of willow, poplar and pine seedlings in Himachal Pradesh
}

Sunita Chandel* and Vijay Kumar

Department of Plant Pathology, Dr. Y.S. Parmar University of Horticulture and Forestry, Nauni, Solan (H.P.) India (Email : vnarwal777@yahoo.com)

\section{ARITCLE INFO}

Received : 05.01 .2020

Revised : 10.03 .2020

Accepted : 23.03.2020

\section{KEY WORDS :}

VAM (Vesicular arbuscular mycorrhiza), Poplar, Willow, Pine, Salix, Rhizosphere
*Corresponding author:

Email : schandelmpp@ rediffmail.com

\begin{abstract}
Poplar and willow are economically-important, fast-growing tree species with the ability to colonize nutrient-poor environments. Willow (Salix sp.) offers a great potential as a source of renewable energy and for bioremediation and polluted environments. To initiate a study on the possible contribution of arbuscular mycorrhiza to this ability, we isolated mycorrhial fungi from in and around the rhizosphere of native poplar (Populus sp.), willow (Salix sp.) and pine (Pinus sp.) seedlings grown in research nurseries at Dr. Y.S. Parmar University of Horticulture and Forestry, Solan (H.P.). Several species of mycorrhizal fungi grew well in the rhizosphere of these trees, were characterized based on morphological studies. The number of spores per $50 \mathrm{~g}$ of rhizosphere soil from pinus, willow and poplar were found to be $1380,1290,1300$ and 540, 490, 530 spores at $106 \mu$ and $250 \mu$ mesh sieves, respectively. The presence of these AM fungi may help explain the ability of these pioneering tree species to grow under nitrogen limitation. Their presence will be helpful in mitigating the losses due to soil borne diseases as well as enhancing the plant vigor.
\end{abstract}

How to view point the article : Chandel, Sunita and Kumar, Vijay (2020). Status of Arbuscular mycorrhiza (AM) in nurseries of willow, poplar and pine seedlings in Himachal Pradesh. Internat. J. Plant Protec., 13(1) : 87-92, DOI : 10.15740/HAS/IJPP/13.1/87-92, Copyright@ 2020: Hind Agri-Horticultural Society. 